\title{
Should the patients with endometriosis be treated as a risk group of pregnancy complications? Single center experience and literature review
}

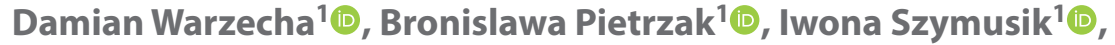 \\ Zuzanna Smiech ${ }^{2}$, Miroslaw Wielgos ${ }^{1}[$ \\ ${ }^{1} 1^{\text {st }}$ Department of Obstetrics and Gynecology, Medical University of Warsaw, Poland \\ ${ }^{2}$ Students Scientific Association at the 1st Department of Obstetrics and Gynecology, Medical University of Warsaw, Poland
}

\begin{abstract}
Objectives: Multidirectional influence of endometriosis on fertility impairments is well known. Altered implantation and placentation among affected patients raised concerns regarding possible negative influence on the course of pregnancy. The primary objective of the study was to assess the course of gestation and the incidence of pregnancy complications among women with endometriosis. It also aimed to determine whether the method of conception might impact the primary results. Material and methods: A single-center cohort study included 64 women with confirmed endometriosis and 296 healthy controls. Data concerning treatment of endometriosis related infertility, course of pregnancy and perinatal outcomes were evaluated.

Results: Patients with endometriosis were older than controls ( $33.6+/-4.2$ y vs $31.8+/-4.6, p=0.01$ ) and more often gave birth for the first time $(87.5 \%$ vs $43.9 \%, p=0.001)$. The age at the time of first delivery was significantly higher within the study group ( $33.1 \mathrm{y}+/-4.1 \mathrm{vs} 29.9+/-4.6, p<0.001$ ). In the study, $81.2 \%$ of patients with endometriosis had the diagnosis of infertility. Patients suffering from endometriosis were significantly more prone to spontaneous placental abruption during pregnancy and delivery $(4.7 \mathrm{vs} 0.3 \%$, odds ratio $=14.5$ ). Several complications occurred more often in endometriotic patients (gestational diabetes mellitus, small-for-gestational-age and anemia); however, without statistical significance. The risk of pregnancy complications was independent from stage of endometriosis and way of conception. The incidences of adverse neonatal outcomes (preterm delivery, low Apgar score, lower birth weight) were similar in both groups.

Conclusions: Endometriosis may adversely affect perinatal outcomes, especially due to increased risk of placenta abruption and operative delivery. Stage of endometriosis and method of conception does not enhance these complications.

Key words: cesarean section; endometriosis; infertility; placenta pathology; pregnancy complications
\end{abstract}

Ginekologia Polska 2020; 91, 7: 383-388

\section{INTRODUCTION}

There are a multitude of possible reasons for decreased fertility among women of reproductive age. Among them is endometriosis, defined as presence of endometrial glands and stroma outside the uterine cavity [1]. Although the pathogenesis of endometriosis is still under debate, it is well known that it affects every part of a woman's reproductive system. The prevalence of endometriosis in the general population is estimated to be 10-15\%; however, among infertile females the rate may increase up to $48 \%[2,3]$. Nevertheless, the symptoms of the disease do not correlate with its' stage, meaning that the real incidence in the general population remains unknown and the prevalence may be underestimated.
Endometriosis can affect the reproductive potential by means of reduced ovarian function, decreased oocyte quality, altered embryo development or implantation failure.

Current literature describes various defects of endometrial functions in patients suffering from endometriosis. Endometrial tissue is characterized by high sensitivity to autocrine and paracrine signaling factors, such as sex hormones or cytokines. Locally unbalanced production of estrogens and cytokines in ectopic endometrium leads to disordered growth and malfunctioning of the tissue [4]. All of the above are involved in altered gene expression in eutopic endometrium and myometrium [5]. Furthermore, inappropriate cytokine secretion causes chronic local and 
systemic inflammatory response and results in the most typical symptoms and signs of endometriosis, such as chronic pelvic pain (especially dysmenorrhea, dyspareunia), pelvic adhesions and distorted pelvic anatomy. Decreased sensitivity to progesterone, due to downregulation of progesterone receptors is the reason why endometriosis is also called 'progesterone-resistant disease' $[6,7]$. The alterations in molecular and cellular profiles of the eutopic endometrium of women with endometriosis were detected. It has been, therefore, hypothesized that endometriosis may influence pregnancy outcomes [8].

There is a strict dependency between proper implantation and placentation. Both are critical for fetal growth and favorable pregnancy outcomes. Nowadays, the correlation between abnormal placentation and several pregnancy complications, such as pregnancy induced hypertension $(\mathrm{PIH})$, preeclampsia, fetal growth restriction, placental abruption (AP) or placenta praevia (PP) is well established. Furthermore, most of them may lead to the iatrogenic preterm birth. All the above may explain why previous investigators raised concerns regarding possible negative influence of endometriosis on the course of pregnancy and possible early pregnancy loss.

\section{Objectives}

The primary objective of the presented study was to assess the course of gestation and the incidence of pregnancy complications among women with confirmed endometriosis. It also aimed to determine whether the way of conception might impact the primary results. According to the available literature this issue has not been investigated among the Polish population before.

\section{MATERIAL AND METHODS}

A single-center cohort study was carried out at the $1^{\text {st }}$ Department of Obstetrics and Gynecology, Medical University of Warsaw. Multiple gestations and pregnancies miscarried prior to 22 weeks were excluded from the study. The authors identified 64 women with endometriosis, confirmed during previous surgical intervention (laparoscopy or laparotomy), who delivered at the Department between January 2015 and December 2018. Women diagnosed with adenomyosis or other anatomical disorders within genital tract not related to endometriosis (e.g. myomas) were excluded from the final analysis due to the suggested additional negative impact on the course of gestation. Data concerning treatment of pre-existing endometriosis, infertility [especially with the usage of assisted reproductive technologies (ART)], course of pregnancy and perinatal outcomes were obtained from medical records. Assessed neonatal outcomes included preterm delivery, Apgar score and birth weight. The stage of endometriosis was conferred according to the revised
American Society for Reproductive Medicine classification (rASRM) [9].

The control group $(C)$ consisted of healthy women (without any known chronic diseases before conception; no suspicion of endometriosis, nor the diagnosis of infertility) who delivered at the Department within the same time frame. Finally, the control group consisted of 296 participants.

The baseline and clinical characteristics of both groups were collected from the patients' medical records. Preterm delivery was defined as birth before 37 completed weeks of gestation, while fetal growth restriction (FGR) as estimated fetal weight (EFW) below the tenth percentile in ultrasound examination [10]. PE, PIH and gestational diabetes mellitus were recognized according to guidelines of The Polish Society of Gynecologists and Obstetricians and The Royal College of Obstetricians and Gynaecologists.

The study was conducted in accordance with the Declaration of Helsinki for Medical Research involving human subjects. The ethical approval was obtained from the Ethics Committee of Medical University of Warsaw (AKBE/99/2019).

\section{Statistical analyses}

Categorical variables were presented as percentages and continuous ones as means with SD (standard deviation). The baseline and clinical data were compared using parametric (t-Student) and nonparametric (Mann-Whitney U) tests. Univariate odds ratios (ORs) with $95 \%$ confidence intervals $(95 \% \mathrm{Cl})$ for the parameters that could affect the course of pregnancy were calculated by Chi-Square test. A multiple logistic regression model was built to estimate which factors influence the risk of pregnancy complications. Statistica 13 software was used for statistical analyses. P-values below the threshold of 0.05 were considered significant. Main calculations were performed for all women with endometriosis. Additional analyses included the adjustment for the stage of endometriosis and the way of conception.

\section{RESULTS}

Baseline characteristics of women with or without endometriosis are presented in Table 1. Patients diagnosed with endometriosis were significantly older $(p=0.01)$ than controls and more often gave birth for the first time $(p=0.001)$. Moreover, the age at the time of first delivery was significantly higher in the study group compared to controls (33.1 years, $\mathrm{SD}=4.1$ vs 29.9, $\mathrm{SD}=4.6, \mathrm{p}<0.01$ ).

All patients from the study group underwent at least one surgical procedure in the past $(62.5 \%$ excision of endometrioma, $15.6 \%$ diagnostic laparoscopy due to pelvic pain or infertility, $6.3 \%$ removal of hydrosalpinx). The mean age at the diagnosis of endometriosis was 29.2 years (SD $=4.5$ ). Most of the women suffered from moderate to severe endo- 


\begin{tabular}{|l|l|l|l|}
\hline Table 1. Baseline characteristics of the groups \\
\hline & $\begin{array}{l}\text { Study } \\
\text { group (SD) }\end{array}$ & $\begin{array}{l}\text { Control } \\
\text { group (SD) }\end{array}$ & $\begin{array}{l}\text { p } \\
\text { value }\end{array}$ \\
\hline Sample size & 64 & 296 & $(-)$ \\
\hline Age [years] & $33.6(4.2)$ & $31.8(4.6)$ & 0.01 \\
\hline BMl before pregnancy $\left[\mathrm{kg} / \mathrm{m}^{2}\right]$ & $22.4(3.8)$ & $23.4(4.6)$ & 0.24 \\
\hline Gestational age at delivery $[$ weeks] & $38.6(1.6)$ & $38.7(2.0)$ & 0.25 \\
\hline Primiparous & $87.5 \%$ & $43.9 \%$ & $<0.001$ \\
\hline Mean birth weight $[\mathrm{g}]$ & $3301(540)$ & $3408(580)$ & 0.09
\end{tabular}

$\mathrm{BMI}$ - body mass index; SD — standard deviation

\begin{tabular}{|c|c|c|c|}
\hline & $\begin{array}{l}\text { Study } \\
\text { group, } \\
\text { n (\%) }\end{array}$ & $\begin{array}{l}\text { Control } \\
\text { group, } \\
\mathrm{n}(\%)\end{array}$ & OR (95\% Cl) \\
\hline $\mathrm{PIH}$ & $5(7.8)$ & $28(9.5)$ & $0.8(0.3-2.2)$ \\
\hline Preeclampsia & $1(1.6)$ & $7(2.4)$ & $0.7(0.1-5.4)$ \\
\hline GDM & $11(17.2)$ & $45(15.2)$ & $1.2(0.6-2.4)$ \\
\hline FGR & $5(7.8)$ & $12(4.1)$ & $2.0(0.7-5.9)$ \\
\hline Hypothyroidism & $11(17.2)$ & $69(23.3)$ & $1.1(0.1-9.8)$ \\
\hline Anemia during pregnancy & $9(14.1)$ & $21(7.1)$ & $2.1(0.9-4.9)$ \\
\hline Placenta previa & $1(1.6)$ & $0(0)$ & $(-)$ \\
\hline Placental abruption & $3(4.7)$ & $1(0.3)$ & $14.5(1.5-140)$ \\
\hline $\begin{array}{l}\text { Imminent fetal asphyxia } \\
\text { during labor }\end{array}$ & $6(9.4)$ & $20(6.8)$ & $1.4(0.5-3.7)$ \\
\hline Caesarean delivery & $43(67.2)$ & $156(52.7)$ & $1.8(1.1-3.2)$ \\
\hline Preterm delivery & $7(10.9)$ & $27(9.1)$ & $1.2(0.5-2.9)$ \\
\hline
\end{tabular}

$\mathrm{Cl}$ - confidence interval; GDM - gestational diabetes mellitus; OR - odds ratio; $\mathrm{PIH}$ - pregnancy induced hypertension; $\mathrm{FGR}$ - fetal growth restriction

metriosis (stage 4-15.2\%, 3-42.4\%, 2-30.3\%, 1-12.1\%). Patients'BMI significantly differed within subsequent stages of endometriosis [stage 1-22.2 $\left(\mathrm{kg} / \mathrm{m}^{2}\right),(\mathrm{SD}=4.9), 2-23.4(4.8)$, 3-20.9 (2.6), 4-24.8 (3.2), $p=0.02$ ]. Moreover, the incidence of overweight and obesity increased with the severity of disease (stage $1-0 \%, 2-30 \%, 3-14 \%$ and $40 \%$ in stage 4), however this factor did not reach statistical significance $(p=0.1)$. Patients BMI did not impact the severity of endometriosis. Due to comparable prognosis and recommendations concerning the treatment of infertility in patients with stage 1 and 2, as well as stage 3 and 4 of endometriosis, these cases were further evaluated together (called $1+2$ and $3+4$ endometriosis).

In the study, $81.2 \%$ of patients with endometriosis had the diagnosis of infertility before (65.6\% primary and $15.6 \%$ secondary). The mean time to conception in the study group equaled 2.6 years $(S D=2.7)$. Also, $42.9 \%$ of women with $1+2$ endometriosis conceived spontaneously, $21.4 \%$ after
Table 3. Pregnancy complications and perinatal outcomes adjusted for the stage of endometriosis and the way of conception

\begin{tabular}{|l|l|l|}
\hline & $\begin{array}{l}\mathbf{1}+\mathbf{2} \text { vs 3 +4 } \\
\text { endometriosis } \\
\text { OR (95\% CI) }\end{array}$ & $\begin{array}{l}\text { Natural } \\
\text { conception/IUI } \\
\text { vs IVF OR (95\% CI) }\end{array}$ \\
\hline PIH & $0.4(0.1-2.6)$ & $0.3(0.1-2.2)$ \\
\hline Preeclampsia & $(-)$ & $(-)$ \\
\hline GDM & $0.4(0.1-1.7)$ & $0.6(0.2-2.3)$ \\
\hline FGR & $1.1(0.1-11.0)$ & $2.4(0.2-22.6)$ \\
\hline Hypothyroidism & $0.4(0.1-1.5)$ & $0.4(01-1.5)$ \\
\hline Anemia during pregnancy & $0.4(0.1-1.8)$ & $0.1(0.1-0.6)$ \\
\hline Placenta previa & $(-)$ & $(-)$ \\
\hline Placental abruption & $(-)$ & $1.1(0.1-13.2)$ \\
\hline Imminent fetal asphyxia & $0.5(0.1-2.9)$ & $1.1(0.2-6.7)$ \\
\hline during labor & $0.3(0.1-1.5)$ & $0.8(0.3-2.5)$ \\
\hline Caesarean delivery & $1.8(0.2-16.0)$ & $0.7(0.1-3.5)$ \\
\hline Preterm delivery &
\end{tabular}

$\mathrm{Cl}$ - confidence interval; GDM - gestational diabetes mellitus; IUI — intrauterine insemination; $\mathrm{OR}$ - odds ratio; $\mathrm{PIH}$ - pregnancy induced hypertension; FGR — fetal growth restriction

intrauterine insemination (IUI) and 35.7\% after in-vitro fertilization (IVF). Finally, $72 \%$ of pregnancies in patients with $3+4$ endometriosis were a result of IVF, $20 \%$ of IUI, while only $8 \%$ were conceived naturally. The incidence of spontaneous pregnancies was significantly higher in patients with stage $1+2$ compared to stage $3+4(p=0.01)$.

The incidence of pregnancy complications among women from the study and control groups is presented in Table 2 . Patients suffering from endometriosis were significantly more prone to spontaneous placental abruption during pregnancy and delivery $(O R=14.5)$. Several complications related to the course of pregnancy occurred more often in endometriotic patients (gestational diabetes mellitus, FGR or anemia); however, without statistical significance.

Endometriosis increased the risk of operative delivery $(O R=1.8)$. The most frequent indication for caesarean section (CS) in the study group was the previous history of infertility/ART (elective CS, 27.9\%) and excessive bleeding/hemorrhage during labor (emergency CS, 13.9\%). Moreover, placental abruption was the most frequent known reason of obstetric hemorrhage. On the contrary, the most frequent reasons to perform CS in the control group included previous caesarean section (18.3\%) and labor arrest of (8.1\%).

Further sub analysis assessed the risk of pregnancy complications adjusted for the stage of endometriosis and the method of conception (Tab. 3). The risk of the analyzed perinatal complications was not related to any of the above. The only feature that differed in patients with endometriosis was the decreased risk of anemia during IVF pregnancy (4.9\% vs $30.4 \%, p=0.01)$. 
Most women in both groups delivered full-term newborns. The rate of preterm deliveries among women diagnosed with endometriosis equaled $10.9 \%$ compared to $9.1 \%$ in healthy controls $(p=0.65)$. Neonatal outcomes were similar among women with and without endometriosis. There was no significant difference in the mean fetal birth weight ( $3301 \mathrm{~g}$ vs $3408 \mathrm{~g}$ in controls, $\mathrm{p}=0.09$ ). There were no significant differences in the incidence of low Apgar scores $\left(<8\right.$ points in $1^{\text {st }}$ and $5^{\text {th }}$ minute of life between both studied groups ( 1.6 vs $3.4 \%, p=0.4$ and 0 vs $1.7 \%$, $\mathrm{p}=0.3$ respectively).

\section{DISCUSSION}

Pregnancy and delivery related complication are the main reasons of maternal and neonatal morbidity [11]. Identifying and close monitoring of patients with increased risk of adverse perinatal outcomes provide an opportunity to improve the quality of maternity care [12].

According to our findings, endometriosis does not seem to increase the risk of most common pregnancy complications such as PIH, preeclampsia, GDM or FGR. The potential correlation between endometriosis and preeclampsia is still a subject of debate. Previous researchers did not find any association between these conditions either [13]. Hadfield et al. obtained similar results from the longitudinal observation of 3239 Australian women with endometriosis diagnosed prior to pregnancy. In comparison to the healthy controls, neither pregnancy hypertension, nor pre-eclampsia occurred more often in the study group [14]. The rate of complications was also independent from the severity of endometriosis. However, according to Berlac et al., women with endometriosis are more prone to suffer from hypertensive disorders during pregnancy: preeclampsia (OR 1.4), severe preeclampsia, eclampsia or HELLP syndrome (OR 1.7 95\%) than healthy controls [15]. Data from Danish reports $(82,793$ singleton pregnancies) also suggest increased risk of pre-eclampsia in affected females $(\mathrm{OR}=1.37,95 \% \mathrm{Cl} 1.06-1.77)$, regardless of the way of conception (natural vs ART) [16]. The results were again confirmed in a cohort study by Farland et al. [17], where the risk of hypertensive disorders in women with endometriosis was also greater ( $R R$ 1.3; 95\% Cl 1.16-1.45).

Tobias et al. evaluated the risk of GDM among women with a history of infertility - they found no association for endometriosis [18]. Subsequent systematic review published by Perez-Lopez et al. [19] also confirmed no association (OR 1.14, 95\% Cl 0.86-1.51). However, Farland et al. concluded that endometriosis was associated with a significantly greater risk of GDM (RR 1.35; 95\% Cl 1.11-1.63). Therefore, even the results from large cohort studies are inconclusive [17].

The incidence of placental abruption differed most between both studied groups in the presented research. Wom- en with endometriosis were at increased, over fourteen-fold, risk of the above complication compared to healthy controls. Moreover, the authors observed higher incidence of placenta previa in the study group ( $1.6 \%$ vs $0 \%$ ), but the result did not reach significance. These conclusions are concordant with the findings of previous researchers (reported OR 2.0-3.99 for placental abruption and 3.9-15.1 for placenta previa) $[13,15,20,21]$.

According to our results, endometriosis seems to be positively correlated with the incidence of elective caesarean sections $(O R=1.8)$. This finding is concordant with previous studies (Porpora et al., Horton et al.) [21, 22]. Nevertheless, vaginal labor does not increase the risk of peritoneal injuries among women who underwent surgery for deep infiltrating endometriosis and may reduce the recurrence of endometriosis symptoms after delivery [23, 24].

Further sub-analyses of pregnancy complications regarding the stage of endometriosis and the method of conception did not show any significant differences between groups.

The incidence of most of the adverse perinatal outcomes increases with the age of the woman in general population. Patients with endometriosis were significantly older than controls (33.6 vs 31.8 years); however, this fact did not bias the end results.

The authors of the presented paper did not evaluate the course of early pregnancies ( $<22^{\text {nd }}$ week of gestation). Few publications hypothesize that endometriosis may be associated with early pregnancy loses (both spontaneous abortion and ectopic pregnancy), but these findings should be carefully interpreted (Farland et al., Porpora et al.) [21]. Further studies should also focus on these issues.

Neonatal outcomes (rate of preterm deliveries, birth weight and Apgar scores) did not differ between women with or without endometriosis. On the other hand, previous researchers gave evidence of increased risk for preterm delivery and neonatal unit admission following delivery among women diagnosed of endometriosis [22].

The women' age is the strongest indicator of fertility impairments in the future. Of women, $81.2 \%$ diagnosed with endometriosis, who delivered at our department, had been diagnosed with infertility before. Furthermore, the average age at the time of the first pregnancy ended with delivery was significantly higher among women with endometriosis compared to healthy controls. The same findings were presented by previous researchers [25]. According to the epidemiological data, endometriosis extends the time to conception (mean time from diagnosis to pregnancy equaled 2 years and 4 months). There is a clear association between endometriosis and infertility due to lower oocyte yield and lower implantation rates. The percentage of known fertility impairments is much higher than the rate observed 
in the general population [26]. Previous studies have reported an inverse correlation between advanced stages of endometriosis and the prognosis for fertility treatments [27]. Apart from chronic pelvic pain and dyspareunia, fertility impairments are the most common symptoms among patients suspected of endometriosis [28]. Moreover, literature data proves an increased risk of infertility, over 8-fold, among endometriotic patients [29].

The problem is additionally enhanced by significant diagnostic delay in recognition of endometriosis. The average time from the onset of first symptoms to the final diagnosis of the disease varies greatly among countries (from 4.4 years in USA, up to 10.4 years in Germany and Austria) [30,31]. The main factors contributing to the above are mainly limited access to gynecological care, time between consultations and high (up to 74\%) rates of false diagnoses. The American Society for Reproductive Medicine classification is the most widely used tool for assessing the clinical stage of endometriosis. In the study group, a higher incidence of late forms of endometriosis was observed (stage III and IV). It may be due to the problem of underestimation of the disease prevalence; however, benefits from performing laparoscopy for minimal endometriosis prior to IVF are still under debate [32].

There are some limitations of the above study. It presents only single-center experience and the results regarding adverse perinatal outcome might not reach significance due to small sample size.

\section{CONCLUSIONS}

To conclude, the history of endometriosis may adversely affect perinatal outcomes, especially due to impaired placentation and increased risk of operative delivery. However, it does not seem to influence neonatal complications as preterm birth, low Apgar score or low birth weight. Since stage of endometriosis have detrimental effect on female fertility, it seems reasonable to raise awareness of possible fertility impairments especially among women with symptoms typical for endometriosis.

\section{Conflict of interest}

The authors declare that there is no conflict of interest.

\section{REFERENCES}

1. Stilley JAW, Birt JA, Sharpe-Timms KL. Cellular and molecular basis for endometriosis-associated infertility. Cell Tissue Res. 2012; 349(3): 849862, doi: 10.1007/s00441-011-1309-0, indexed in Pubmed: 22298022.

2. Mishra V. Prevalence; Characteristics and Management of Endometriosis Amongst Infertile Women: A One Year Retrospective Study. JOURNAL OF CLINICAL AND DIAGNOSTIC RESEARCH. 2015, doi: 10.7860/jcdr/2015/13687.6125.

3. Morassutto C, Monasta L, Ricci G, et al. Incidence and Estimated Prevalence of Endometriosis and Adenomyosis in Northeast Italy: A Data Linkage Study. PLOS ONE. 2016; 11(4): e0154227, doi: 10.1371/journal. pone.0154227.
4. Kitawaki J, Noguchi T, Amatsu T, et al. Expression of aromatase cytochrome $\mathrm{P} 450$ protein and messenger ribonucleic acid in human endometriotic and adenomyotic tissues but not in normal endometrium. Biol Reprod. 1997; 57(3): 514-519, doi: 10.1095/biolreprod57.3.514, indexed in Pubmed: 9282984.

5. Fox C, Morin S, Jeong JW, et al. Local and systemic factors and implantation: what is the evidence? Fertil Steril. 2016; 105(4): 873-884, doi: 10.1016/j.fertnstert.2016.02.018, indexed in Pubmed: 26945096.

6. Kim BG, Yoo JY, Kim TH, et al. Aberrant activation of signal transducer and activator of transcription-3 (STAT3) signaling in endometriosis. Hum Reprod. 2015; 30(5): 1069-1078, doi: 10.1093/humrep/dev050, indexed in Pubmed: 25750101.

7. Sharkey AM, Macklon NS. The science of implantation emerges blinking into the light. Reprod Biomed Online. 2013; 27(5): 453-460, doi: 10.1016/j.rbmo.2013.08.005, indexed in Pubmed: 24055396.

8. Lessey BA, Kim JJ. Endometrial receptivity in the eutopic endometrium of women with endometriosis: it is affected, and let me show you why. Fertil Steril. 2017; 108(1): 19-27, doi: 10.1016/j.fertnstert.2017.05.031, indexed in Pubmed: 28602477.

9. Revised American Society for Reproductive Medicine classification of endometriosis: 1996. Fertil Steril. 1997; 67(5): 817-821, doi: 10.1016/s0015-0282(97)81391-x, indexed in Pubmed: 9130884.

10. ACOG Practice Bulletin No. 204 Summary: Fetal Growth Restriction. Obstet Gynecol. 2019; 133(2): 390-392, doi: 10.1097/AOG.0000000000003071, indexed in Pubmed: 30681535.

11. Domanski G, Lange $A E$, Ittermann $T$, et al. Evaluation of neonatal and maternal morbidity in mothers with gestational diabetes: a population-based study. BMC Pregnancy Childbirth. 2018; 18(1): 367, doi: 10.1186/s12884-018-2005-9, indexed in Pubmed: 30200916.

12. Gibson C, Rohan AM, Gillespie KH. Severe Maternal Morbidity During Delivery Hospitalizations. WMJ. 2017; 116(5): 215-220, indexed in Pubmed: 29357211.

13. Harada T, Taniguchi F, Onishi K, et al. Japan Environment \& Children's Study Group. Obstetrical Complications in Women with Endometriosis: A Cohort Study in Japan. PLoS One. 2016; 11(12): e0168476, doi: 10.1371/journal.pone.0168476, indexed in Pubmed: 28005934.

14. Hadfield RM, Lain SJ, Raynes-Greenow $\mathrm{CH}$, et al. Is there an association between endometriosis and the risk of pre-eclampsia? A population based study. Hum Reprod. 2009; 24(9): 2348-2352, doi: 10.1093/humrep/dep123, indexed in Pubmed: 19443457.

15. Berlac JF, Hartwell D, Skovlund CW, et al. Endometriosis increases the risk of obstetrical and neonatal complications. Acta Obstet Gynecol Scand. 2017; 96(6): 751-760, doi: 10.1111/aogs.13111, indexed in Pubmed: 28181672.

16. Glavind MT, Forman A, Arendt LH, et al. Endometriosis and pregnancy complications: a Danish cohort study. Fertil Steril. 2017; 107(1): 160-166, doi: 10.1016/j.fertnstert.2016.09.020, indexed in Pubmed: 27743699.

17. Farland LV, Prescott J, Sasamoto N, et al. Endometriosis and Risk of Adverse Pregnancy Outcomes. Obstet Gynecol. 2019; 134(3): 527-536, doi: 10.1097/AOG.0000000000003410, indexed in Pubmed: 31403584.

18. Tobias DK, Chavarro JE, Williams MA, et al. History of infertility and risk of gestational diabetes mellitus: a prospective analysis of 40,773 pregnancies. Am J Epidemiol. 2013; 178(8): 1219-1225, doi: 10.1093/aje/kwt110, indexed in Pubmed: 23956097.

19. Pérez-López FR, Martínez-Domínguez SJ, Viñas A, et al. Health Outcomes and Systematic Analyses (HOUSSAY) Project. Endometriosis and gestational diabetes mellitus risk: a systematic review and meta-analysis. Gynecol Endocrinol. 2018; 34(5): 363凶369, doi: 10.1080/09513590.2017.1397115, indexed in Pubmed: 29105527.

20. Takemura $Y$, Osuga $Y$, Fujimoto $A$, et al. Increased risk of placenta previa is associated with endometriosis and tubal factor infertility in assisted reproductive technology pregnancy. Gynecol Endocrinol. 2013; 29(2): 113-115, doi: 10.3109/09513590.2012.706669, indexed in Pubmed: 22835092.

21. Porpora MG, Tomao F, Ticino A, et al. Endometriosis and Pregnancy: A Single Institution Experience. Int J Environ Res Public Health. 2020; 17(2), doi: 10.3390/ijerph17020401, indexed in Pubmed: 31936225.

22. Horton J, Sterrenburg M, Lane S, et al. Reproductive, obstetric, and perinatal outcomes of women with adenomyosis and endometriosis: a systematic review and meta-analysis. Hum Reprod Update. 2019; 25(5): 592-632, doi: 10.1093/humupd/dmz012, indexed in Pubmed: 31318420.

23. Bulletti $C$, Montini $A$, Setti PL, et al. Vaginal parturition decreases recurrence of endometriosis. Fertil Steril. 2010; 94(3): 850-855, doi: 10.1016/j. fertnstert.2009.04.012, indexed in Pubmed: 19524893. 
24. Allerstorfer $C$, Oppelt $P$, Enzelsberger $\mathrm{SH}$, et al. Delivery after Operation for Deeply Infiltrating Endometriosis. Biomed Res Int. 2016; 2016: 8271452, doi: 10.1155/2016/8271452, indexed in Pubmed: 27517050.

25. Saraswat L, Ayansina DT, Cooper KG, et al. Pregnancy outcomes in women with endometriosis: a national record linkage study. BJOG. 2017; 124(3): 444-452, doi: 10.1111/1471-0528.13920, indexed in Pubmed: 26887349.

26. Vander Borght $M$, Wyns $C$. Fertility and infertility: Definition and epidemiology. Clin Biochem. 2018; 62: 2-10, doi: 10.1016/j.clinbiochem.2018.03.012, indexed in Pubmed: 29555319.

27. Harb HM, Gallos ID, Chu J, et al. The effect of endometriosis on in vitro fertilisation outcome: a systematic review and meta-analysis. BJOG. 2013; 120(11): 1308-1320, doi: 10.1111/1471-0528.12366, indexed in Pubmed: 23834505.

28. Dunselman GAJ, Vermeulen N, Becker C, et al. European Society of Human Reproduction and Embryology. ESHRE guideline: management of women with endometriosis. Hum Reprod. 2014; 29(3): 400-412, doi: 10.1093/humrep/det457, indexed in Pubmed: 24435778.

29. Ballard KD, Seaman HE, de Vries CS, et al. Can symptomatology help in the diagnosis of endometriosis? Findings from a national case-control study--Part 1. BJOG. 2008; 115(11): 1382-1391, doi: 10.1111/j.1471-05 28.2008.01878.x, indexed in Pubmed: 18715240.

30. Hudelist G, Fritzer N, Thomas A, et al. Diagnostic delay for endometriosis in Austria and Germany: causes and possible consequences. Hum Reprod. 2012; 27(12): 3412-3416, doi: 10.1093/humrep/des316, indexed in Pubmed: 22990516.

31. Soliman AM, Fuldeore M, Snabes MC. Factors Associated with Time to Endometriosis Diagnosis in the United States. JWomens Health (Larchmt). 2017; 26(7): 788-797, doi: 10.1089/jwh.2016.6003, indexed in Pubmed: 28440744.

32. Daniilidis A, Pados G. Comments on the ESHRE recommendations for the treatment of minimal endometriosis in infertile women. Reprod Biomed Online. 2018; 36(1): 84-87, doi: 10.1016/j.rbmo.2017.10.103, indexed in Pubmed: 29100809. 